\title{
IDENTIFIKASI SISTEM TURBIN GAS MENGGUNAKAN METODE ANALISIS KORELASI DAN ALGORITMA REALISASI
}

\author{
Dody Azhar Hariyadi*), Dwindra Wilham Maulana**), Amrizal Nainggolan, Naila Zahra, Syaina Ulfah Azhara, Azka \\ Muji Burohman, Cahyoni Marhanani, Ardian Primadi \& Augie Widyotriatmo***)
}

Program Studi Instrumentasi dan Kontrol, FTI, ITB Jl. Ganesha 10, Bandung 40132,

Jawa barat , Indonesia

(corresponding author) dody.azhar@gmail.com*)

dwindramaulana@gmail.com**), augie@tf.itb.ac.id ${ }^{\star \star \star)}$

\begin{abstract}
Abstrak
Makalah ilmiah ini membahas pemodelan sistem sebuah Turbin Gas 1.2 PLTGU Grati. Turbin Gas merupakan salah satu sistem yang kompleks. Pemodelan dilakukan dengan cara mengidentifikasi sistem berdasarkan hubungan input dan output. Dilakukan pengamatan data input-output selama empat hari. Data input yang digunakan adalah berupa data governor bahan bakar, sedangkan data output didapatkan dari pengukuran rpm dan daya. Mula-mula, dari informasi input dan output dilakukan identifikasi non-parametrik untuk menghasilkan representasi sistem berupa respon impuls dengan menggunakan metode analisis korelasi. Selanjutnya, dari respon impuls yang didapatkan tersebut dilakukan realisasi untuk mendapatkan estimasi fungsi transfer dari sistem Turbin Gas.
\end{abstract}

Kata Kunci: identifikasi sistem, parametrik, non parametrik, analisis korelasi, realisasi.

\section{Pendahuluan}

Turbin gas merupakan suatu mesin yang banyak digunakan untuk aplikasi industri maupun transportasi. Salah satu pemakaian turbin gas adalah untuk membangkitkan tenaga listrik. Pengoperasian dari turbin gas yang kompleks membutuhkan suatu kontrol yang tepat dan efisien. Untuk membuat hal tersebut, dibutuhkan suatu pemodelan dari turbin gas tersebut.

Pemodelan turbin gas telah banyak dilakukan sebelumnya, diantaranya memakai metode matematis sederhana dengan model yang dikembangkan berdasarkan data eksperimen pada power plant turbin [2]. Metode tersebut valid pada daerah operasi tertentu. Pemodelan turbin gas lainnya dilakukan dengan meggunakan model terstruktur ARX dengan identifikasi parameter didapatkan dari percobaan input-output dari model yang telah disusun sebelumnya [3][4].

Pada makalah ilmiah ini akan dibahas pemodelan turbin gas dengan menggunakan metode analisis korelasi dan algoritma realisasi berdasarkan data input-output operasional dari suatu turbin gas 1.2 PLTGU Grati Pasuruan, tipe mesin 701D buatan Mitsubishi Heavy Industry. Identifikasi sistem dilakukan menggunakan metode analisis korelasi yang menghasilkan representasi sistem berupa respon impuls [1]. Selanjutnya dilakukan realisasi dengan mula-mula menentukan matriks Hankel agar dapat dilakukan perhitungan Singular Value Decomposition (SVD) untuk mendapatkan estimasi orde sistem dan fungsi transfer sistem turbin gas. Estimasi fungsi transfer turbin gas yang diperoleh tersebut dapat memberikan representasi dari dinamika sistem. Validasi model dilakukan dengan cara memasukkan data input operasional harian pada model hasil identifikasi sistem, sehingga didapatkan estimasi output yang kemudian dibandingkan dengan output terukur turbin gas.

\section{Deskripsi Sistem}

Suatu sistem memiliki karakteristik statis dan dinamis yang bisa berubah seiring waktu dikarenakan adanya penurunan performa setiap subsistem, maupun akibat adanya penggantian komponen di sistem tersebut. Perubahan ini juga dipengaruhi oleh pola pengoperasian dan maintenance. Identifikasi sistem/pemodelan diperlukan untuk dapat mengevaluasi sistem, seperti seberapa optimal sistem kontrol pada sistem.

PLTGU Grati-Pasuruan milik PT. Indonesia Power telah berdiri sejak tahun 1995 dan berumur kurang lebih 20 tahun. Identifikasi sistem 
dilakukan pada Turbin Gase GT 1.2. Turbin gas tersebut beroperasi 24 jam dengan bahan bakar gas. Profil load atau beban per-hari mengikuti beban sistem Jamali (Jawa-Madura-Bali) dan ketersediaan suplai bahan bakar gas. Blok diagram turbin gas dapat dilihat pada Gambar 1.

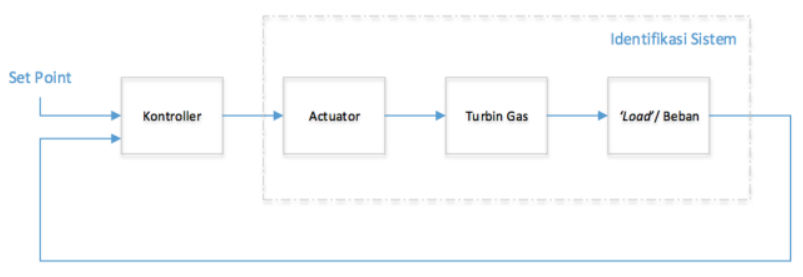

Gambar 1. Diagram blok turbin gas

Identifikasi sistem turbin gas dilakukan dengan menggunakan data input dan output sistem. Data Input merupakan nilai keluaran pengontrol. Nilai keluaran tersebut menunjukkan pengaturan bukaan aktuator/valve bahan bakar turbin gas. Data output yang digunakan merupakan nilai daya yang dihasilkan oleh turbin gas, dalam hal ini parameter daya terkait nilai torsi dan beban turbin gas. Pengambilan data dilakukan selama empat hari untuk keperluan identifikasi dan data dua hari berikutnya untuk keperluan validasi model.

\section{Deskripsi Metoda Identifikasi}

Pada bagian ini akan dibahas metode identifikasi sistem yang akan digunakan pada makalah ini yaitu analisis korelasi dan algoritma realisasi.

\subsection{Analisis Korelasi}

Metoda analisis korelasi adalah salah satu metoda identifikasi sistem non-parametrik. Dengan metoda ini, data input-output sistem digunakan untuk mengestimasi respon impuls sistem.

Suatu sistem dapat didefinisikan dengan persamaan (1).

$y(t)=G_{0}(z) u(t)+v(t)$

Dengan $\mathrm{Go}_{\mathrm{o}} \mathrm{z}$ ) adalah fungsi transfer sistem, input $\mathrm{u}(\mathrm{t})$ dan noise $\mathrm{v}(\mathrm{t})$. Representasi sistem dapat dituliskan juga dalam bentuk konvolusi seperti pada persamaan (2)

$y(t)=\sum_{k=0}^{\infty} g_{0}(k) u(t-k)+v(t)$

Dimana go(k) adalah respon impuls dari sistem Go.
Dengan asumsi bahwa noise $\mathrm{v}(\mathrm{t})$ tidak berkorelasi dengan input $\mathrm{u}(\mathrm{t})$, maka diperoleh persamaan Wiener-Hopf pada persamaan (3).

$R_{y u}(\tau)=\sum_{k=0}^{\infty} g_{0}(k) R_{u}(\tau-k)$

Dengan $\mathrm{R}_{\mathrm{yu}}$ adalah kovarian input-output dan $\mathrm{R}_{\mathrm{u}}$ adalah autokovarian input. Dalam kasus input $\mathrm{u}(\mathrm{t})$ adalah white noise, autokovarian input akan bernilai 1 hanya pada $\tau=0$.

$R_{u}(\tau)=\sigma_{u}^{2} \delta(\tau)$

Dimana $\sigma_{u}^{2}$ varian input $\mathrm{u}(\mathrm{t})$ dan $\delta(\tau)$ fungsi impulse. Dari persamaan (3) dan (4) diperoleh estimasi respon impuls.

$\hat{g}(\tau)=\frac{\hat{R}_{y u}(\tau)}{\sigma_{u}^{2}}$

Dimana $\hat{R}_{y u}$ adalah estimator kovarian inputoutput dengan jumlah data pengukuran yang terbatas.

Dalam kasus input $u(t)$ bukan white noise, filter $\mathrm{L}(\mathrm{z})$ akan diterapkan pada input dan output sebagai pre-whitening filter.

$u_{F}=L(z) u(t)$

$y_{F}=L(z) y(t)$

Sehingga dari persamaan (1) dan (6) akan didapatkan:

$y_{F}=G_{0}(z) u_{F}(t)+L(z) v(t)$

Dengan demikian respon impuls $g_{0}(k)$ dapat diestimasi menggunakan data input-output yang telah terfilter.

\subsection{Algoritma Realisasi}

Suatu sistem dapat direpresentasikan dengan model ruang keadaan seperti pada persamaan (8).

$x(k+1)=A x(k)+B u(k)$

$y(k)=C x(k)+D u(k)$

Atau dalam bentuk fungsi transfer,

$G(z)=\sum_{k=0}^{\infty} g(k) z^{-k}=D+C(z I-A)^{-1} B$

Dari persamaan (9), matriks D dapat diperoleh dari respon impuls untuk $\mathrm{k}=0$. 


$$
g(k)= \begin{cases}D & k=0 \\ C A^{k-1} B & k \geq 1 .\end{cases}
$$

Dibuktikan bahwa matriks A, B dan C dapat diperoleh dari respon impuls untuk $k \geq 1$ menggunakan matriks Hankel pada persamaan (11)[5].

$$
H_{r, c}=\left[\begin{array}{cccc}
g(1) & g(2) & \ldots & g(c) \\
g(2) & g(3) & \ldots & g(c+1) \\
\vdots & \vdots & & \vdots \\
g(r) & g(r+1) & \ldots & g(r+c-1)
\end{array}\right]
$$

Dari persamaan (10) matriks Hankel juga dapat dituliskan

$H_{r, c}=\left[\begin{array}{c}C \\ C A \\ \vdots \\ C A^{r-1}\end{array}\right]\left[\begin{array}{llll}B & A B & \ldots & A^{c-1} B\end{array}\right]$

Solusi untuk persamaan (11) dan (12) didapatkan menggunakan Singular Value Decomposition (SVD) [6]. Dimana matriks Hankel dapat dituliskan menjadi,

$H_{n}=U_{n} \Sigma_{n} V_{n}^{T}$

Dimana $U_{n}$ dan $V_{n}$ adalah $n$ kolom pertama dari matriks unitary $U$ dan $V\left(U_{n}{ }^{\top} U_{n}=V_{n}{ }^{\top} V_{n}=1\right)$, dan $\Sigma_{n}$ adalah diagonal matriks dengan $n$ nilai pertama yang signifikan dari matriks diagonal dekomposisi nilai singular $\Sigma$.

Lebih lanjut persamaan (13) dapat dituliskan sebagai berikut,

$H_{n}=U_{n} \Sigma_{n}{ }^{1 / 2} \Sigma_{n}{ }^{1 / 2} V_{n}^{T}$

Dari persamaan (14) diperoleh,

B: kolom pertama dari $H_{2}=\Sigma_{n}{ }^{1 / 2} V_{n}^{T}$

$B$ : baris pertama dari $H_{1}=U_{n} \Sigma_{n}{ }^{1 / 2}$

$A=\Sigma_{n}{ }^{-1 / 2} U_{n}^{T} \overleftarrow{H} V_{n} \Sigma_{n}{ }^{-1 / 2}$

Dengan,

$\overleftarrow{H}_{r, c}=\left[\begin{array}{cccc}g(2) & g(3) & \ldots & g(c+1) \\ g(3) & g(4) & \ldots & g(c+2) \\ \vdots & \vdots & \ddots & \vdots \\ g(r+1) & g(r+2) & \ldots & g(r+c)\end{array}\right]$

\section{Simulasi dan Diskusi}

Pengamatan dilakukan selama empat hari dengan waktu pengambilan sampel setiap 30 menit. Data mentah yang berupa input dan output ini diolah dengan metode analisis korelasi untuk mendapatkan estimasi dari respon impuls. Data input dan output yang diambil langsung dari pengukuran di lapangan diperlihatkan pada Gambar 2.

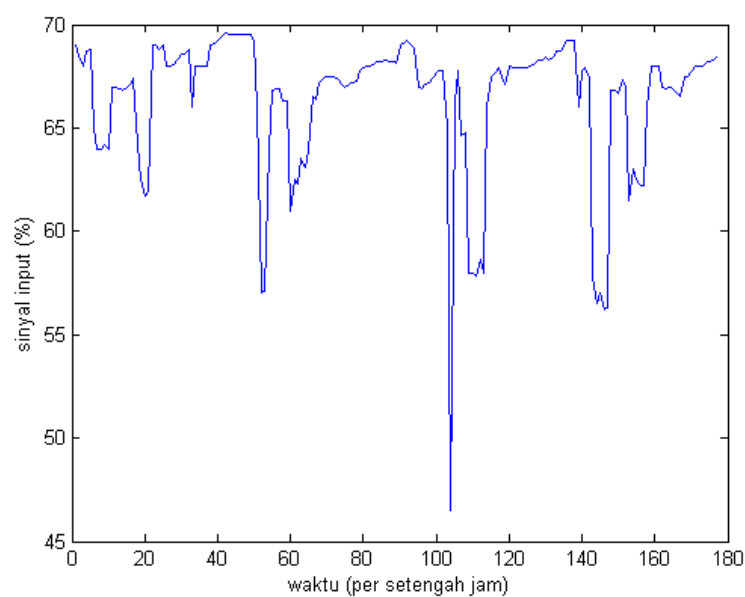

(a)

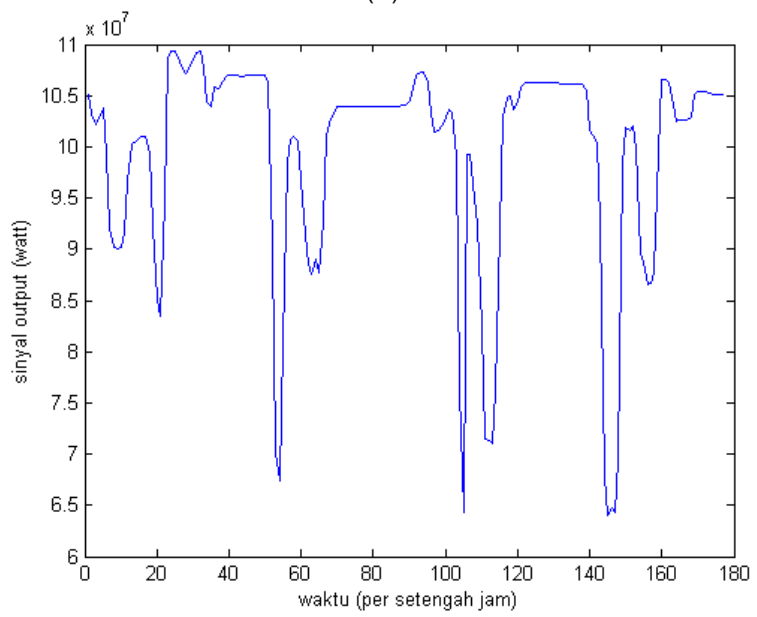

(b)

Gambar 2. (a) Data input, (b) Data output turbin gas

\subsection{Analisis Korelasi pada Turbin Gas}

Data yang dibutuhkan untuk melakukan analisis korelasi adalah input yang memiliki sifat whitenoise dan barisan data output yang merupakan fungsi dari input. Pada Gambar 3 terlihat bahwa sinyal input belum memiliki sifat white noise, sehingga perlu dilakukan pre-whitening filter. Sesuai persamaan (6), dalam identifikasi ini filter pre-whitening $L(z)$ yang diterapkan pada data input $u(k)$ memiliki orde $n=30$. Sehingga 
diilustrasikan filter tersebut adalah dengan persamaan (19)

$L(z)=1+a_{1} \cdot z^{-1}+a_{2} \cdot z^{-2}+\cdots+a_{30} \cdot z^{-30}$

Gambar 4 menunjukkan estimasi respon impuls yang merupakan penyelesaian dari persamaan (5).

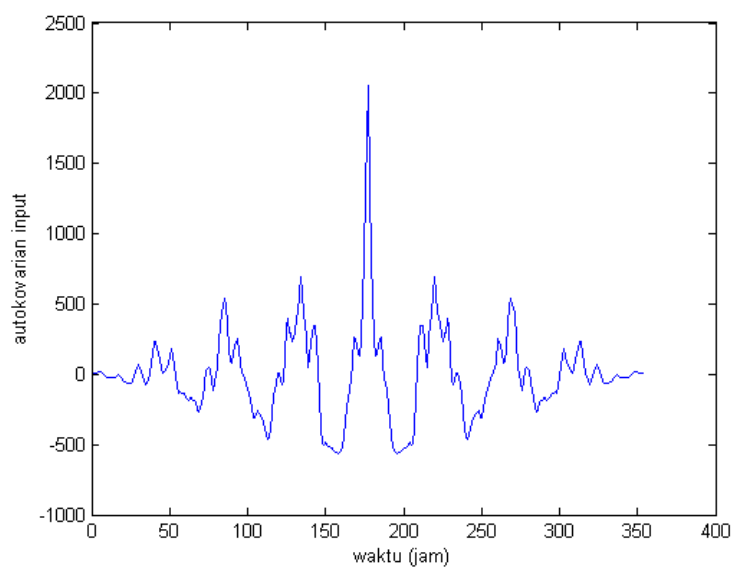

Gambar 3. Autokovarians dari sinyal input

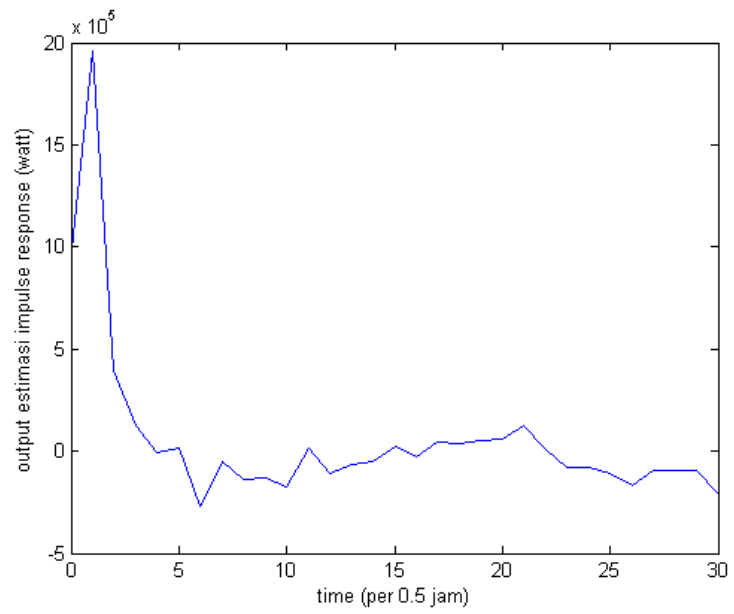

Gambar 4. Estimasi respon impuls hasil analisis korelasi

\subsection{Model Parametrik Turbin Gas dengan Algoritma Realisasi}

Dari hasil estimasi respon impuls sebelumnya, dibentuk matriks Henkel seperti pada persamaan (11) dengan ukuran $15 \times 15$. Dengan SVD didapat nilai-nilai singular seperti pada Gambar 5. Hasil SVD menunjukkan bahwa hanya terdapat satu nilai yang dominan atau bernilai tidak nol secara signifikan yaitu $2,1441 \times 10^{6}$. Dari nilai tersebut dapat ditarik kesimpulan bahwa nilai orde dari model yang akan ditentukan secara parametrik adalah $n=1$. Nilai singular $(\sigma)$ pada kolom kedua matriks dan seterusnya bisa dianggap terlalu jauh dibandingkan dengan nilai singular pada kolom pertama, sehingga tidak akan berpengaruh signifikan pada model. Setelah ditentukan orde dari model yang akan dibuat adalah orde satu, maka dapat ditentukan nilai-nilai dari parameter $A$, $B$, C, dan $D$ pada bentuk umum sistem ruang keadaan dengan persamaan (15), (16) dan (17). Sehingga persamaan model ruang keadaan turbin gas yang diperoleh dari hasil estimasi diberikan pada persamaan (20)

$$
\begin{aligned}
& x(k+1)=0,2385 x(k)-1394,4 u(k) \\
& y(k)=-1394,4 x(k)+949270 u(k)
\end{aligned}
$$

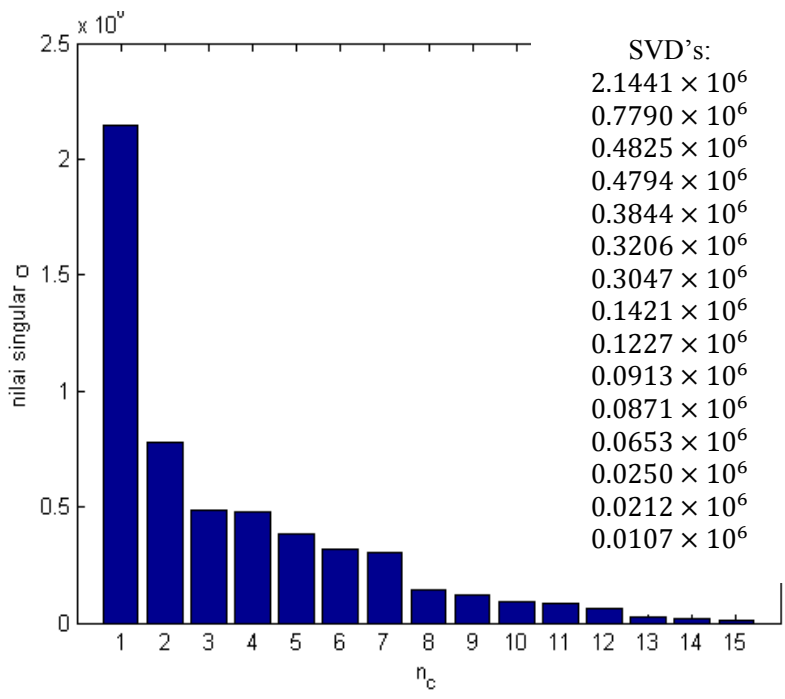

Gambar 5. Hasil SVD untuk penentuan orde sistem

\subsection{Validasi Model}

Untuk memvalidasi hasil dari identifikasi sistem digunakan data turbin gas selama dua hari dengan periode sampling 30 menit. Perbandingan antara estimasi output identifikasi sistem dan data output hasil pengukuran di lapangan dapat dilihat pada Gambar 6. Grafik berwarna hijau menunjukkan estimasi output, sedangkan grafik berwarna merah menunjukkan data output pengukuran. Dapat dilihat bahwa estimasi output memiliki representasi yang serupa dengan nilai pengukuran sebenarnya. Nilai root mean square galat dari kedua nilai tersebut adalah 2,88 \%. Puncakpuncak yang terdapat pada grafik pun menunjukkan dinamika yang bersesuaian. Puncak pada grafik output pengukuran di lapangan dan output simulasi dapat ditemukan pada waktuwaktu yang sama, yaitu $t=11,20,35,57,65$, dan 78. 


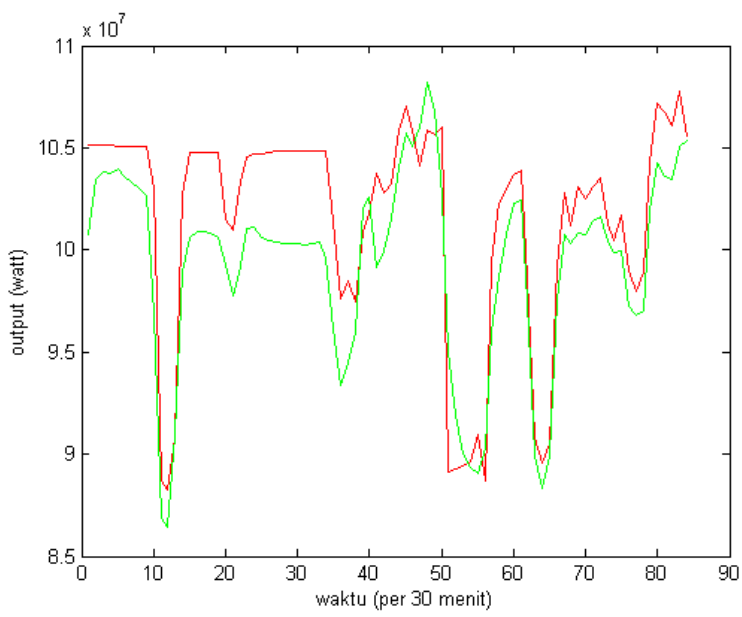

Gambar 6. Perbandingan estimasi output dan output terukur

\section{Kesimpulan}

Berdasarkan hasil identifikasi sistem dan validasi model, dapat disimpulkan bahwa estimasi model parametrik yang disusun dari analisis korelasi dan algoritma realisasi cukup merepresentasikan sistem turbin gas. Dengan didapatkannya model parametrik tersebut maka pemahaman lebih lanjut mengenai dinamika turbin gas dapat dikembangkan, khususnya secara matematis. Identifikasi sistem ini dapat menghasilkan estimasi yang lebih baik dengan memperkecil waktu sampling data input output.

\section{Ucapan Terima Kasih}

Terimakasih kepada Tim Pemeliharaan Kontrol Instrumen PT. Indonesia Power UBP Perak Grati atas data yang telah disediakan untuk keperluan identifiksi sistem ini.

\section{Daftar Pustaka}

[1] Lennart Ljung, "System Identification: Theory for the user", PTR Prentice Hall, 1987. (references)

[2] W. I. Rowen, "Simplified Mathematical Representation of Heavy-Duty Turbin Gases", ASME J. Eng. Power, vol. 105, pp. 865-869, 1983

[3] Zoleikha Abdollahi, Maryam Hantehzadeh, Ali K. Sedigh, "Multilinear Modelling and Identification of the V94.2 Turbin Gase for Control System Design Purposes," IEEE Conference Publications, Pages: 295 - 300, DOI: 10.1109/ EMS.2010.55, 2010

[4] Widiana H. Imania, Katherin Indriawati, Ya'umar, "Perancangan pengendalian prediktif berpengawasan pada pembangkit listrik tenaga gas dan uap (PLTGU) Gresik dengan metode desentralisasi" Jurnal Teknik POMITS vol.1 No.1 pp 1-6, 2012

[5] B.L. Ho and R.E. Kalman, "Efficient construction of linear state variable models from input/output functions," Regelungstechnik, vol. 14, pp. 545-548, 1966.

[6] H.P. Zieger and J. McEwen, "Approximate linear realizations of given dimansion via Ho's algorithm," IEEE Trans. Automat. Control, vol. AC-19, pp. 153, 1974. 